\title{
CONSELHO MUNICIPAL DE EDUCAÇÃO DE PALMAS: CRIAÇÃO, COMPOSIÇÃO, FUNÇÕES E AÇÕES
}

\author{
Municipal Council of Education of Palms: Creation, Composition, Functions and \\ Actions
}

Consejo Municipal de Educación de Palmas: Creación, Composición, Funciones y Acciones

Desafios

Artigo Original

Original Article Artículo Original

\section{Jorcelyo Alencar Lima ${ }^{1}$, Jacira Brito Tavares ${ }^{1}$, Jacinta Brito Tavares ${ }^{1}$}

${ }^{1}$.Programa de Pós-graduação do Mestrado Profissional em Gestão de Políticas Públicas na Universidade Federal do Tocantins - UFT, Palmas, Brasil.

*Correspondência: 405 Sul Ql 24 Lote 6, Alameda 11, Palmas - TO, CEP: 77015-642. e-mails: j.alencar2008@hotmail.com.

Artigo recebido em 10/04/2020 aprovado em 30/10/2020 publicado em 30/12/2020.

\section{RESUMO}

O presente artigo tem como objetivo analisar as funções e ações do Conselho Municipal de Educação de Palmas-TO, fundada nos conceitos e princípios universais dos Conselhos Gestores e de Educação, quer seja no âmbito federal, estadual ou municipal. O aparato teórico se ancorou em teses, dissertações e artigos científicos para iluminar o processo investigatório, no sentido de se estabelecerem como parâmetros para análise dos dados coletados através da observação in loco, levantamento de documentos e realização de entrevistas com a presidência e conselheiros da instituição. Face a análise desde os dados históricos da criação, da composição, funções e ações do referido Conselho, a pesquisa nos encaminha a conclusões prévias que assume o Conselho como cumpridor das funções fundantes, como normativa, consultiva, fiscalizadora, propositiva e de controle social, em detrimento da função mobilizadora que compromete o diálogo e a coparticipação da comunidade, para que possa exercer a cidadania em seu sentido pleno.

Palavras-chaves: Conselho Municipal de Educação. Controle Social. Cidadania Deliberativa.

\section{ABSTRACT}

This article aims to analyze the functions and actions of the Municipal Council of Palmas-TO Education, founded on the universal concepts and principles of the Management and Education Councils, whether at the federal, state or municipal levels. The theoretical apparatus was anchored in theses, dissertations and scientific articles to illuminate the investigative process, in order to establish themselves as parameters for analysis of data collected through on-site observation, document collection and interviews with the presidency and directors of the institution. In view of the analysis from the historical data of the creation, composition, functions and actions of that Council, the research forwards us to previous conclusions that the Council assumes as a compliance with the founding functions, such as normative, consultative, supervisory, propositional and social control, to the detriment of the mobilizing function that compromises the dialogue and co-participation of the community, so that it can exercise citizenship in its full sense.

Keywords: Municipal Council of Education. Social Control. Citizenship Deliberative.

\section{RESUMEN}

Este artículo tiene como objetivo analizar las funciones y acciones del Consejo Municipal de Educación de PalmasTO, fundado en los conceptos y principios universales de los Consejos de Administración y Educación, ya sea a nivel federal, estatal o municipal. El aparato teórico se basó en tesis, disertaciones y artículos científicos para iluminar el proceso de investigación, en el sentido de establecerse como parámetros para el análisis de los datos recopilados 
a través de la observación in situ, la encuesta de documentos y entrevistas con la presidencia y asesores de la institución. . En vista del análisis de los datos históricos de la creación, composición, funciones y acciones del Consejo antes mencionado, la investigación nos lleva a conclusiones previas que el Consejo asume como cumplimiento de las funciones fundacionales, como control normativo, consultivo, de supervisión, proposicional y social. en detrimento de la función movilizadora que compromete el diálogo y la coparticipación de la comunidad, para que pueda ejercer la ciudadanía en su sentido completo.

Descriptores: Consejo Municipal de Educación. Control social. Ciudadania Deliberativo.

\section{INTRODUÇÃO}

A Constituição Federal de 1988, a partir de um contexto descentralizador administrativamente em conjunto com a ideia de participação popular, institucionaliza os Conselhos enquanto agentes de mudança nos modelos de gestão das políticas públicas, tendo em vista serem plurais, permanentes e autônomos, na construção da democracia e cidadania deliberativa.

Constituídos por representantes da sociedade civil e do poder público, os Conselhos Gestores de forma em geral têm como atividades: normatização, fiscalização, controle e deliberação sobre as políticas públicas em qualquer setor de atividade, de maneira a estabelecer um novo paradigma nas relações entre Estado e sociedade.

Enquanto instituição, os Conselhos Gestores podem ser criados por meio de leis, com regimentos deliberados pelos membros conselheiros de forma a contemplar as funções normativa, fiscalizadora, de controle social, propositiva, consultiva, de assessoramento, deliberativa e mobilizadora.

Nesse diapasão, encontram-se inseridos os Conselhos Municipais de Educação, que corroboram com a gestão municipal de ensino no sentido de normatização das leis por meio da elaboração de regras, regimentos e execuções adequadas à realidade local, entre outras atividades.

O Conselho Municipal de Educação de Palmas-TO, objeto da presente pesquisa, é considerado relativamente novo, tendo sido criado em 1990, porém só iniciou suas atividades em 1997.
Contando apenas com duas décadas de existência, torna-se alvo de investigação, uma vez que sedia diversas políticas públicas direcionadas a um sistema de ensino básico, público e privado, bem como uma variedade de escolas, inseridas em uma população aproximada de 292 mil habitantes.

Assim sendo, o trabalho tem como objetivo analisar a composição, função, ação e funcionamento do Conselho supracitada e ainda condução das tomadas de decisões e deliberações em reuniões; interação com a sociedade civil e o poder público; controle e fiscalização das políticas públicas no sistema municipal de educação.

No que diz respeito aos procedimentos metodológicos, inicialmente adotou-se um caráter bibliográfico e documental com utilização do método descritivo-dedutivo, uma vez buscou-se identificar, registrar e caracterizar fatores e variáveis relacionadas ao fenômeno ou processo, para entendimento e contextualização sobre dos Conselhos Gestores.

Em relação à pesquisa de campo, seu início se deu em fevereiro de 2019, com visitas mensais ao Conselho Municipal de Educação de Palmas-TO com a finalidade de observar a rotina e levantar dados relacionados às deliberações, normatizações, reuniões, assembleias e ações em geral, bem como a interação entre sociedade civil e Poder Público.

O artigo apresenta conceitos e características de um conselho gestor para adentrar no âmbito dos conselhos Municipais de Educação, evidenciando as bases legais vigentes, suas funções e funcionalidade, o que vem embasar a análise do Conselho alvo da 
pesquisa que é o Conselho Municipal de Educação de Palmas - TO.

\section{DESENVOLVIMENTO}

Os conselhos gestores, como são órgãos públicos que têm a missão de garantir, na sua especificidade, o direito constitucional da cidadania, tornaram-se instituições de relevância no contexto das políticas públicas a partir da constituição de 1988, que se disseminaram pelos estados e municípios do País, fazendo valer os princípios constitucionais que prescrevem a participação da sociedade na condução das políticas públicas e da legislação regulamentadora.

Segundo Gohn (2001), os conselhos são canais de participação que articulam representantes da população e membros do poder público estatal em práticas que dizem respeito à gestão de bens públicos. Como tais, viabilizam um novo paradigma de relações entre o Estado e a sociedade, uma vez que favorecem a participação dos diferentes segmentos sociais na formulação das políticas sociais. Através deles a população tem acesso aos territórios de decisões políticas e criando sistemas de vigilância sobre as gestões públicas, implicando em maior cobrança de prestação de contas do executivo.

\section{Conselho Gestor: uma discussão terminológica e ideológica}

A lexia complexa conselho gestor contempla o conceito de gestão que, segundo Gomes et al. (2008) apud Cançado, Tenório e Pereira (2011) “[...] pensar em gestão social, é pensar além da gestão de políticas públicas, mas sim estabelecer as articulações entre ações de intervenção e de transformação do campo social, que é uma noção mais ampla, e que não se restringe à esfera público-governamental (...)”.
Com a mesma concepção, argumentam Botrel, Araújo e Pereira (2010), também citados pelos autores que "a gestão social se desenvolve no âmbito da esfera pública, na qual se sobressaem as organizações públicas não-estatais e o interesse público da sociedade, além de proporcionar condições à emancipação dos indivíduos, baseando-se na democracia deliberativa, na formação da consciência crítica de seres humanos dotados de razão."

No que concerne à cidadania deliberativa, fundamenta Tenório ( 2008 a, 2008 b) apud Cançado, Tenório e Pereira (2011) que “(...) a legitimidade das decisões deve ter origem em processos de discussão orientados pelos princípios da inclusão, do pluralismo, da igualdade participativa, da autonomia e do bem comum" e acrescenta que a cidadania deliberativa "[...] faz jus à multiplicidade de formas de comunicação [...]" e "[...] une os cidadãos em torno de um auto entendimento ético" (TENÓRIO, 2008b) apud Cançado, Tenório e Pereira (2011).

Referendando as concepções supracitadas, os autores endossam que a esfera pública seria o espaço de intermediação entre Estado, sociedade e mercado, bem como a cidadania deliberativa seria o processo participativo de deliberação baseado essencialmente no entendimento (e não no convencimento ou negociação) entre as partes (TENÓRIO, 2008a, 2008b) apud Cançado, Tenório e Pereira (2011) e “[...] o procedimento da prática da cidadania deliberativa na Esfera Pública é a participação" (TENÓRIO, 2008b, p. 171, grifos do autor) apud Cançado, Tenório e Pereira (2011).

Um aspecto de relevância que atravessa o conceito de gestão pauta-se no âmbito da ação comunicativa, onde a interação através da linguagem constrói sentidos nos contextos e co-textos em que se inserem os sujeitos com as suas possíveis posições, 
derivando desse encontro a capacidade de decidir, reconstruir, deliberar, assumir posições ideológicas que corroboram o ato de gerir.

Nessa dimensão, Tenório (2008 b) apud Cançado, Tenório e Pereira (2011) funda-se na concepção de que a gestão social se baseia no entendimento, estreitamente vinculado com a linguagem, pois, "no processo de gestão social [...] a verdade é a promessa de consenso racional, [...] não é uma relação entre o indivíduo e a sua percepção de mundo, mas sim um acordo alcançado por meio da discussão crítica, da apreciação intersubjetiva".

A pluralidade semântica envolvida na lexia conselho gestor reúne sentidos que culminam com numa unidade de significação, uma vez que os dois conceitos são atravessados pelas mesmas formações ideológicas que dialogam com o mesmo pensar e o mesmo fazer: planejar juntos, decidir juntos, participar juntos.

Gomes (2015) caracteriza os conselhos como órgãos públicos de composição paritária entre a sociedade e o governo, criados por lei, regidos por regulamento aprovado por seu plenário, tendo caráter obrigatório uma vez que os repasses de recursos ficam condicionados à sua existência, e que assumem atribuições consultivas, deliberativas e/ou de controle. Apresentam diversos formatos condicionados às suas ações focalizadas, através de conselhos gestores de programas governamentais ou à elaboração, implantação e controle de políticas públicas, por meio de conselhos de políticas setoriais, definidos por leis federais para concretizarem direitos de caráter universal, como saúde, educação e cultura.

Fundamentam Przworki, 1994 e Dahl, 1989 (apud Gomes, 2015), ao discutir sobre os conselhos e a democracia deliberativa, que há no movimento conselhista um descontentamento com uma visão minimalista de democracia, presente na teoria democrática contemporânea, na qual ela é reduzida a um "procedimento de eleger governantes", uma vez que a estrutura social que envolve interesses conflitantes e a inviabilidade na prática de consertar os interesses direcionados a um determinado alvo.

Por sua vez, acrescenta o autor que a complexidade da estrutura social contemporânea, também o procedimento democrático clássico, baseado na simples agregação de decisões individuais, impõe novas limitações à realização dos ideais de igualdade política e soberania popular.

Nesse diapasão, argumenta Dahl (1989) apud Gomes (op cit|) que para concretizar os ideais de uma postura essencialmente democrática, seria necessário que atendesse às seguintes condições:

1. O voto de cada eleitor fosse uma manifestação autônoma de preferência entre as alternativas apresentadas; 2. Cada manifestação tivesse o mesmo peso; 3. A alternativa mais votada fosse declarada a vencedora; 4. Qualquer membro que considerasse uma alternativa qualquer preferível às alternativas disponíveis para votação pudesse inseri-la entre as apresentadas à votação; 5 . Todos os indivíduos possuíssem informações idênticas sobre as alternativas; 6 . As alternativas vencedoras (líderes ou políticas) substituíssem as alternativas perdedoras; 7. As ordens dos servidores públicos eleitos fossem executadas; 8 . No interstício eleitoral, todas as decisões tomadas fossem decorrentes ou executivas das decisões tomadas na fase da eleição; ou que as novas decisões tomadas também fossem determinadas pelas sete condições precedentes, operando, contudo, sob circunstâncias institucionais diferentes. (DAHL,1989 apud GOMES 2015)

Tão fundamental quanto o caráter democrático dos conselhos é a sua eficiência, que é da responsabilidade da sociedade, uma vez que compete a ela contribuir para uma maior eficiência no uso dos recursos públicos, principalmente pelo exercício de controle sobre os governantes. Esta atribuição atravessou movimentos de reforma do Estado das 
últimas duas décadas, notadamente em um contexto em que o perfil tradicional dos governos abre discussões para alargar o conceito de governança.

Nesse entorno, é reconhecida a existência e a conveniência da participação ativa das estruturas de poder localizadas fora das instituições formais de governo, para o desenvolvimento sustentável dos países. A sociedade civil tem aqui um papel preponderante na gestão da coisa pública, notadamente, o controle por concorrência administrada, o controle por resultados e o controle social.

Fundamentando-se no conceito de controle social elaborado por Garrelli, 1983, como o "conjunto de meios de intervenção, quer positivos ou negativos, acionados por cada sociedade ou grupo social a fim de induzir os próprios membros a se conformar às normas que a caracterizam", o controle social deve ser exercido pela sociedade numa perspectiva de individualidade, projetando os interesses sobre cada membro que constitui o todo, recaindo sobre cada um os direitos e deveres como resultado desse controle.

\section{Conselho de educação: bases legais e funções}

Como todo conselho gestor, um Conselho de Educação busca assegurar a cidadania no que diz respeito fundamentalmente à garantia dos direitos à educação formal, cujas funções constituem uma obrigação pública imposta por lei que deve ser executada por um órgão colegiado, formado por membros que se reúnem em uma colegialidade, horizontalmente organizada.

A horizontalidade estabelecida entre os membros do colegiado configura uma coordenação, onde não haja hierarquia, mas que todos os membros se posicionem no mesmo plano, concorrendo dentro do universo plural para a construção de uma vontade majoritária e consensual no organismo conselheiro.

Construir uma vontade singular dentro da pluralidade é exercer a cidadania no sentido de manifestar as diversas funções de um Conselho de Educação, principalmente, a função normativa, uma vez que é através dela que um conselheiro interpreta a legislação, na missão de normatizar ou disciplinar assuntos infraconstitucionais.

Como o ato normativo se dá por meio de pareceres e resoluções, ele deve ter previsão legal no exercício da execução do ordenamento jurídico que lhe dá fundamento, já que não podem deixar de ser compatíveis com e decorrentes da legislação e com a que lhe dá o fundamento maior de validade: a Constituição. Nesse sentido é que se evidencia a capacidade de produzir normas por meio da criação de um órgão normativo por lei, onde a lei estabelecida pelos representantes eleitos pelo voto popular confere uma competência para um órgão colegiado apropriado incumbido de atos administrativos específicos (JAMIL KURY, 2006).

Dessa forma, a função normativa é uma função derivada do e pelo poder legislativo em harmonia e cooperação com os outros poderes. Concomitante a essa função concebida como fundante da missão dos Conselhos de Educação estão as funções consultiva e de assessoramento.

Nesta perspectiva é que a Lei no 9.394/96 das Diretrizes e Bases da Educação Nacional (LDBEN), por força do disposto no art. 22, XXIV, da Constituição Federal, recepciona pela Lei n ${ }^{\circ}$ 9.131/95, artigos $8^{\circ}$ e $9^{\circ}$, o já criado Conselho Nacional de Educação e incumbe os Estados, Distrito Federal e Municípios a criação de seus órgãos normativos dentro de seus sistemas de ensino. 
A LDBEN prevê no artigo 11, inciso I, que os municípios incumbir-se-ão de "organizar, manter e desenvolver os órgãos e instituições oficiais dos seus sistemas de ensino, integrando-os às políticas e planos educacionais da União e dos Estados". Nesse diapasão, os Conselhos Municipais de Educação constituem instituições que devem integrar o Sistema Municipal de Ensino.

Os Conselhos Municipais de Educação têm, entre outras atribuições, a tarefa de regulamentar o funcionamento dos sistemas municipais com base no que estabelece a Constituição Federal de 1988 e a LDBEN, promulgada em 1996, construindo seus próprios sistemas de ensino ou permanecendo integrados aos sistemas estaduais.

Diante da flexibilização permitida em Lei, os Conselhos Municipais de Educação, de acordo com a sua forma de criação e organização podem exercer função mobilizadora, propositiva, deliberativa, normativa e fiscalizadora, competindo a ela organizar a oferta da educação básica no âmbito do município em parceria com os gestores municipais, com o papel de articulação e mediação das demandas educacionais da sociedade, além de definir as condições de funcionamento, o que inclui questões relativas à organização pedagógica e definição de normas e legislação, bem como a elaboração dos Planos Municipais de Educação.

O Conselho Municipal de Educação, no exercício da função consultiva, deve atender as consultas a que for submetido, tanto pelo poder público, como secretarias ou órgãos gestores de educação municipal, como entidades da sociedade civil e cidadãos em geral, acerca de assuntos de legislação educacional e sua aplicabilidade no âmbito educacional. Por sua vez, a função propositiva é executada através da emissão de opiniões e sugestões em torno do planejamento educacional e formulação de políticas educacionais no município.

No que tange à função normativa, se o município tem seu sistema próprio de ensino, compete ao Conselho Municipal interpretar a legislação educacional e elaborar normas complementares no âmbito do município, como definição de diretrizes para a elaboração de regimentos escolares, autorização para funcionamento de estabelecimentos de educação infantil, critérios para avaliação e promoção dos alunos, desde que respeitada a legislação vigente, através de aproveitamento de estudos.

A função fiscalizadora e de controle social das políticas públicas e cumprimento da legislação é exercida pelo Conselho Municipal através do contato com os responsáveis para a prestação dos esclarecimentos necessários ou através de sindicância, para propor sansões previstas em lei e, se necessário, formalizar denúncia junto aos órgãos competentes, como o Ministério Público, o Tribunal de Contas e a Câmara Municipal.

O exercício da função mobilizadora reporta à promoção de discussões e estímulo à participação da sociedade no processo de elaboração das políticas públicas e ações na área educacional, mantendo o acompanhamento e controle da sua execução.

Os Conselhos Municipais, por exercerem a função normativa, tem também o poder de deliberação, exercendo, dessa forma, a Função Deliberativa, com o poder de aprovação de regimentos e estatutos, credenciamento de escolas, autorização de funcionamento de cursos, série e ciclos, bem como da aprovação de propostas curriculares.

O acúmulo de funções confere, portanto, aos Conselhos a capacidade de concretizar a gestão democrática no âmbito da educação municipal a partir da participação da população no que tange às políticas 
educacionais locais e definição dos objetivos e metas da Educação Básica no município.

\section{Conselho municipal de educação de Palmas: descrição, caracterização e análise a partir dos dados coletados.}

O Conselho Municipal de Educação de Palmas - TO foi criado por meio da Lei Municipal $\mathrm{n}^{\circ}$ 44, de 21 de março de 1990, porém, só realizou sua primeira reunião ordinária em 20 de junho de 1997, ficando por todo esse tempo sem nenhuma ação. A partir daí se estabeleceu como um órgão autônomo do Sistema Municipal de Educação, com as funções que lhe são peculiares: função normativa, consultiva, mobilizadora, fiscalizadora, propositiva e de controle social.

Desvinculado das questões referentes ao financiamento da Educação até 2005, uma vez que até então era da responsabilidade do FUNDEF o acompanhamento, a fiscalização e o controle social dos recursos, somente em dezembro daquele ano é que os membros do Conselho Municipal de Educação CME-PALMAS-TO e do Conselho de Acompanhamento e Controle Social do FUNDEFCMFM-PALMAS-TO decidiram por realizar reuniões e trabalhos em conjunto.

Com a Lei Federal $n^{\circ}$ 11.494, de junho de 2007, que regulamentou o FUNDEB - Fundo Nacional de Manutenção e Desenvolvimento da Educação Básica e de Valorização dos Profissionais da Educação, ficou determinada a obrigatoriedade de criação do Conselho de Acompanhamento e Controle Social do referido fundo.

Com a Lei Municipal n ${ }^{\circ} 1.461$, de 13 de março de 2007, o Conselho Municipal de Educação ficou constituído por duas câmaras autônomas: Câmara da Educação Básica e Câmara do FUNDEB, com presidência e incumbência específicas, através de diversos segmentos que tratam das questões pedagógicas e financeiras, a saber: a Câmara de Educação Básica é constituída por representantes da Secretaria Municipal da Educação; representante do Sindicato dos Trabalhadores da Educação; representante dos Diretores das Unidades de Educação e Ensino da Rede Pública do Sistema Municipal de Educação; representante de docentes dos cursos de licenciatura das Instituições de Educação Superior; representante dos Conselhos Escolares das Unidades de Educação e Ensino da Rede Pública do Sistema Municipal de Educação; representante do Conselho Municipal da Criança e do Adolescente; representante do Sindicato das Escolas Privadas e representante da Coordenadoria Municipal de Juventude e Esportes.

Já a Câmara do FUNDEB é constituída por representantes da Secretaria Municipal da Educação; representante dos professores da educação básica pública municipal; representante dos diretores das escolas públicas municipais; representante dos servidores técnico-administrativos das escolas públicas municipais; representante do Conselho Tutelar; representantes dos pais de alunos da educação básica pública municipal e representantes dos estudantes da educação básica pública municipal.

De acordo com o site do Conselho Municipal de Educação de Palmas, são atribuições do referido Conselho:

I.. promover a participação da sociedade civil no planejamento, no acompanhamento e na avaliação da educação municipal;

II. zelar pela qualidade pedagógica e social da educação no SME;

III. zelar pelo cumprimento da legislação vigente, no SME;

IV. participar da elaboração e acompanhar a execução e a avaliação do Plano Municipal de Educação de Palmas; 
V. assessorar os demais órgãos e instituições do Sistema Municipal de Educação no diagnóstico dos problemas e deliberar a respeito de medidas para aperfeiçoá-lo;

VI. emitir pareceres, resoluções, indicações, instruções e recomendações sobre assuntos do Sistema Municipal de Educação de Palmas, em especial, sobre autorização de funcionamento, credenciamento e supervisão de estabelecimentos de ensino públicos e privados de seu sistema, bem como a respeito da política educacional nacional;

VII. manter intercâmbio com os demais Sistemas de Educação dos municípios e do Estado do Tocantins;

VIII. analisar as estatísticas da educação municipal anualmente, oferecendo subsídios aos demais órgãos e instituições do Sistema Municipal de Educação de Palmas;

IX. emitir pareceres, resoluções, indicações, instruções e recomendações sobre convênio, assistência e subvenção a entidades privadas filantrópicas, confessionais e comunitárias, bem como seu cancelamento;

$\mathrm{X}$. acompanhar o recenseamento e a matrícula da população em idade escolar para a educação infantil e ensino fundamental, em todas as suas modalidades; XI. mobilizar a sociedade civil e o Estado para a inclusão de pessoas com necessidades educacionais especiais, preferencialmente, no sistema regular de ensino;

XII. dar publicidade quanto aos atos do Conselho Municipal de Educação;

XIII. mobilizar a sociedade civil e o Estado para a progressiva extensão da jornada escolar para tempo integral;

XIV. promover eventos para discussão de temas relevantes da educação em nível nacional, estadual e municipal;

$\mathrm{XV}$. participar da elaboração e acompanhar a execução da política educacional do município de Palmas, no âmbito público e privado, pronunciando, em especial, sobre a ampliação de rede de escolas e a localização de prédios escolares;

XVI. acompanhar e/ou propor a articulação da área educacional com programas de outras secretarias;

XVII. participar na elaboração das políticas de reconhecimento, profissionalização e valorização dos profissionais da educação. (Prefeitura Municipal de Palmas-Conselho Municipal de Educação)
Até meados do ano em curso, o Conselho Municipal de Palmas reunia-se em sala dentro do prédio-sede da Secretaria Municipal de Educação, contando com a colaboração de uma servidora pública municipal, responsável por auxiliar nas funções de secretaria. Após, com a mesma estrutura de pessoal, passou a reunir-se no Centro de Educação de Jovens e Adultos Jandira Torres, localizada no bairro Aureny III.

A estrutura organizacional do Conselho Municipal de Educação de Palmas é formada por duas Câmaras, sendo uma, Câmara de Educação Básica e, outra, do FUNDEB. O quadro a seguir detalha as principais funções de cada instância bem como sua composição.

As matérias comuns às duas Câmaras serão estudadas e deliberadas no Conselho Pleno, que é formado pelos 19 conselheiros titulares, sendo assinadas pelos presidentes das respectivas câmaras, do Conselho e conselheiros presentes.

Face aos dados coletados no sítio do Conselho Municipal de Educação de Palmas e através de entrevista à presidente e a conselheiros, sobre questões relacionadas à estrutura e funcionamento do Conselho na gestão atual, evidencia-se que conta com um potencial humano comprometido com a eficácia do Conselho, em meio às suas diversas funções e bases legais.

Primeiramente, no que diz respeito à escolha da direção, que é constituída por 38 membros, sendo 19 efetivos e 19 suplentes, dos quais 10 constituem a Câmara de Educação Básica e 9 a Câmara do FUNDEB, todos se submetem a eleição em reunião ordinária do Conselho, após terem sido indicados como conselheiros pela Secretaria de Educação do Município ou por outros conselhos, como Conselho 
representante de diretores, representante do conselho

tutelar, dentre outros.

Quadro 1. Função e Composição do Conselho Municipal de Educação de Palmas.

\begin{tabular}{|c|c|}
\hline Organização & $\begin{array}{c}1^{\text {a }} \text { Câmara } \\
\text { EDUCAÇÃ̃ BÁSICA } \\
\end{array}$ \\
\hline Função & $\begin{array}{l}\text { Estudar as leis e demais normativas que regulam o ensino; zelar pela qualidade pedagógica e social da } \\
\text { educação no SME; zelar pelo cumprimento da legislação vigente; emitir pareceres, resoluções, indicações, } \\
\text { instruções e recomendações sobre assuntos de interesse, em especial, sobre autorização de funcionamento, } \\
\text { credenciamento e supervisão de estabelecimentos de ensino públicos e privados de seu sistema, bem como } \\
\text { a respeito da política educacional nacional; acompanhar a elaboração, execução e avaliação da política } \\
\text { educacional do município, no âmbito público e privado, pronunciando sobre a ampliação da rede pública e } \\
\text { a localização de seus prédios escolares. }\end{array}$ \\
\hline Composição & $\begin{array}{l}\text { Constituída por } 9 \text { conselheiros, sendo } 2 \text { representantes da Secretaria Municipal da Educação e } 1 \text { do } \\
\text { Sindicato dos Trabalhadores da Educação, } 1 \text { dos Diretores das Unidades de Educação e Ensino da Rede } \\
\text { Pública do Sistema Municipal de Educação, } 1 \text { dos docentes dos cursos de licenciatura das Instituições de } \\
\text { Educação Superior, } 1 \text { dos Conselhos Escolares das Unidades de Educação e Ensino da Rede Pública do } \\
\text { Sistema Municipal de Educação, } 1 \text { do Conselho Municipal da Criança e do Adolescente, } 1 \text { do Sindicato das } \\
\text { Escolas Privadas e } 1 \text { da Coordenadoria Municipal de Juventude e Esportes. }\end{array}$ \\
\hline Organização & $\begin{array}{ll} & 2 \text { câmara } \\
& \text { FUNDEB } \\
\end{array}$ \\
\hline & 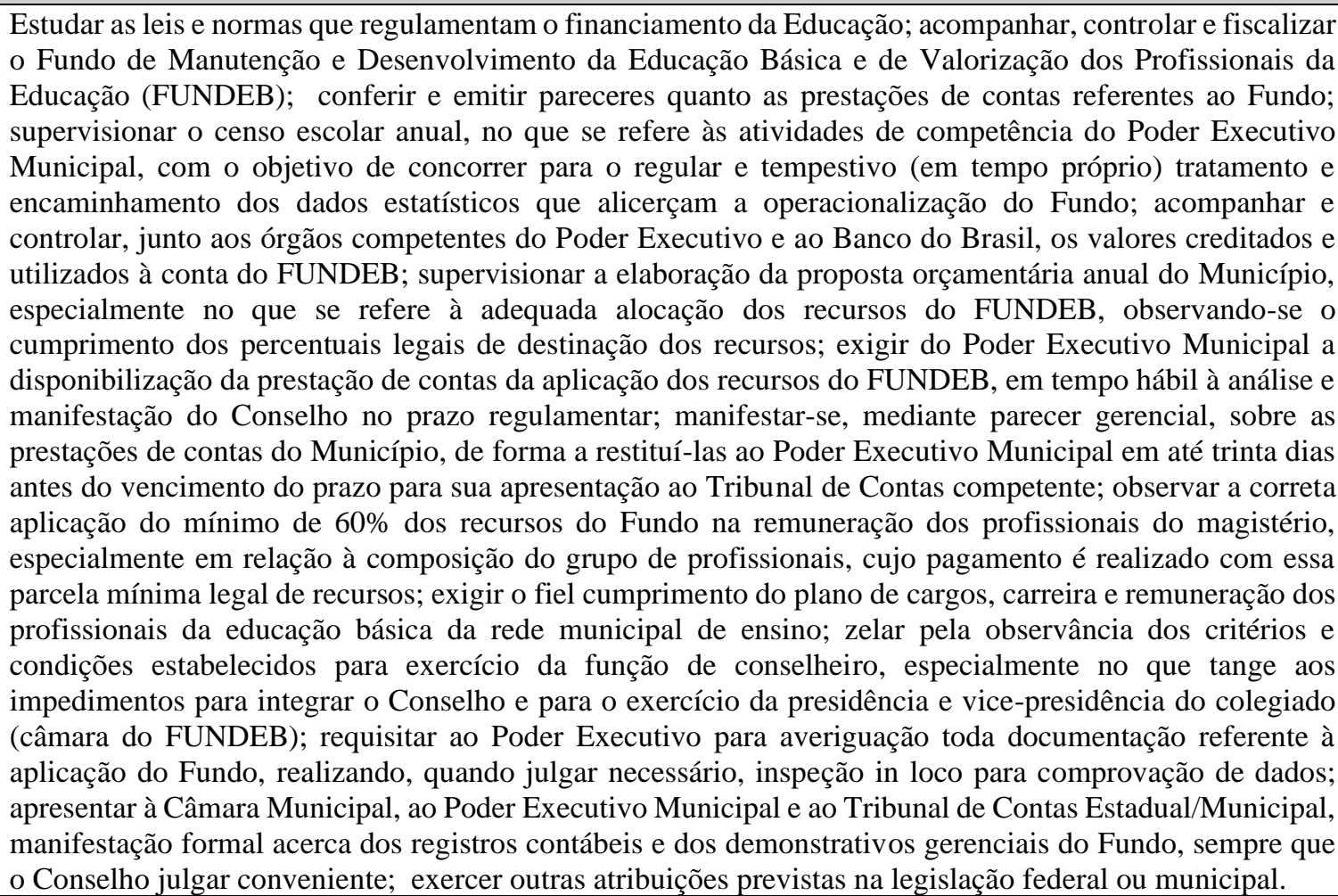 \\
\hline Composição & $\begin{array}{l}\text { Constituída por } 10 \text { conselheiros, sendo } 2 \text { representantes da Secretaria Municipal da Educação, } 1 \text { dos } \\
\text { professores da educação básica pública municipal, } 1 \text { dos diretores das escolas públicas municipais, } 1 \text { dos } \\
\text { servidores técnico-administrativos das escolas públicas municipais, } 1 \text { do Conselho Tutelar, } 2 \text { dos pais de } \\
\text { alunos da educação básica pública municipal e } 2 \text { dos estudantes da educação básica pública municipal. }\end{array}$ \\
\hline
\end{tabular}

Fonte: Elaboração com base na Lei Municipal nº 1461, de 13/3/2007.

Para a representação de pais e docentes, estes

são escolhidos em assembleia das categorias. Após

eleição da presidente, ocorre a nomeação por Ato-
Decreto da Prefeitura Municipal, o que concede o direito de posse. Quanto aos representantes da sociedade civil, ou seja, os conselheiros que não têm 
vínculo com a Prefeitura Municipal, estes são nomeados através de autos públicos.

No cumprimento das suas funções, o Conselho demonstrou eficácia principalmente no exercício da função normativa e deliberativa, uma vez que todas as medidas legais, regimentos internos, tomadas de decisões, autorizações, credenciamentos, elaboração de planos de educação, metas, são resolvidas em reuniões democráticas em que, além da pauta proposta pela mesa presidente a partir da demanda, os conselheiros têm o direito de incluir pontos, que são todos decididos pelo colegiado, prevalecendo o voto da maioria.

Embora a presidente do Conselho tenha autonomia maior, quando se fere às duas Câmaras, da Educação Básica e do FUNDEB, que possuem presidências próprias, ela se porta simplesmente como conselheira, ou seja, as presidências das câmaras têm toda autonomia de decisão; a não ser nos casos em que as Câmaras submetam as decisões à presidência do Conselho Municipal de Educação.

Um aspecto negativo encontrado evidencia-se quanto à função mobilizadora, uma vez que não há qualquer esclarecimento de que a sociedade conhece o Conselho, suas funções e ações, o que inviabiliza uma participação direta. Além de outros fatores que possam justificar a não participação da sociedade, evidencia-se a omissão do Conselho, no sentido de divulgar a sua existência, exemplo disso é o site como único meio de comunicação entre o Conselho e a sociedade. No entanto, encontra-se completamente desatualizado.

Ao final do primeiro semestre de 2019, foi realizada eleição para nova formação do Conselho Municipal de Educação de Palmas, biênio 2019/2021, o qual teve sua composição renovada em aproximadamente $21 \%$ (vinte e um) por cento.

\section{APRESENTAÇÃO DOS RESULTADOS}

No que concerne à atuação do Conselho Municipal de Educação de Palmas-TO, foi aplicada uma pesquisa por meio de análise documental, observação direta, realização de entrevistas e aplicação de questionários junto aos membros do referido órgão.

Inicialmente foi entrevistada a presidente do Conselho Municipal de Educação de Palmas - TO, a senhora Rute Rodrigues. Questionada sobre o tempo de existência do referido órgão, a mesma relatou que desde 1999 e regulamentado a partir de 2001. Acrescentou que: "Fui conselheira no biênio 20172019 e agora reconduzida de 2019-2021, como presidente",

"Eu sou uma conselheira indicada pelo Executivo, pela Secretaria Municipal de Educação, mas o critério tem várias indicações. Tem os representantes de diretores, representante do Conselho Tutelar, representantes de pais, de professores, representante dos Conselhos Escolares".

Quanto à participação em outros Conselhos, a mesma disse não participar de nenhum outro. Acrescentou que: "Faço parte hoje do Fórum Permanente de Educação de Palmas também, que é um colegiado que estuda e discute as políticas educacionais no âmbito do município”.

Perguntada sobre o modo de escolha dos representantes, a mesma respondeu que:

Nessa escolha o conselho envia o ofício para as entidades indicarem esses representantes das Universidades, porque tem representante da educação superior, da educação básica (SEDUC), que também é solicitada a indicar seus representantes. Também o Conselho Tutelar, representantes de pais, de estudantes, de diretores. Eles fazem assembleia e indicam esses representantes para estarem no Conselho. Tem o sindicato também que indica, via ofício, sua representatividade. 
Sobre a composição, ela respondeu que: "É composto por 38 membros, sendo 19 titulares e 19 suplentes. São 10 da Câmara do FUNDEB e 9 da Educação Básica". Em relação à estrutura: "O Conselho hoje é estruturado pelo Pleno, composto por 38 membros e dividido em 2 Câmaras que têm autonomia para apreciar e aprovar matérias específicas. Desses, 19 são titulares e 19 suplentes”.

Também foi questionado sobre uma reunião acontecida no mesmo dia da aplicação da entrevista, em que um dos assuntos foi o credenciamento e autorização de funcionamento do curso da Educação Infantil. Perguntada sobre como ocorre o processo, a mesma informou que:

É o seguinte: a unidade educacional, quando ela passa a existir, ela procura ao Conselho Municipal toda a documentação necessária para ela se credenciar ao sistema e também receber a autorização de funcionamento do curso. Existe uma resolução com todos esses critérios para que as unidades possam dar entrada na documentação. Elas montam o processo e protocolam junto ao Conselho. Após isso, existe uma comissão de verificação in locu que vai até a unidade, verifica, monta o parecer e o conselheiro analisa todo esse processo, faz o seu parecer e traz para apreciação do Pleno e aprovação. Após isso, a unidade sendo aprovada, é publicada no diário oficial.

Sobre a representação entre Estado e Sociedade, a entrevistada relatou que: "A própria lei já estabelece quem são os representantes. A lei já define a representatividade". No que diz respeito à Presidência do Conselho, a mesma disse que:

O procedimento foi assim: após a nomeação, que é feita por ato, decreto da Prefeita Municipal, foi dada a posse aos conselheiros e feita a primeira reunião. $\mathrm{Na}$ reunião, todos os conselheiros titulares podem ser candidatar, colocar o nome deles para serem candidatos. E aí no momento dessa abertura, dessa possibilidade, eu coloquei o meu nome para apreciação dos pares e foi colocado em votação. Colocado em votação, eu fui eleita com a maioria dos votos.
A mesma acredita que o fato de já ter participado de gestões anteriores, credenciou-a a ser eleita em virtude de sua atuação na Câmara da Educação Básica e também por já ser pesquisadora na área de políticas públicas e de gestão.

Questionada sobre o processo eleitoral, a entrevistada relatou que:

Quem vota são todos os conselheiros titulares. No caso, os 19 conselheiros titulares é que votam para Presidente do Conselho. Agora como tem as Câmaras, cada uma escolhe o seu Presidente. Então são três Presidentes: o do CME Pleno, que julga matérias que são amplas, que todos os conselheiros vão deliberar e discutir; e as outras, das matérias que são específicas de cada Câmara.

Sobre a autonomia das matérias em votação:

Eles têm total autonomia nas matérias respectivas a eles. No conselho da Câmara, eu posso colocar porque sou conselheira e sou representante da Câmara de Educação Básica, então eu posso participar. Agora no FUNDEB não, porque eu não participo lá diretamente. Nas matérias que são de interesse geral, eu posso colocar minha opinião.

Válido ressaltar que dentre os Presidentes nas gestões anteriores, a entrevistada é a única mulher a presidir o referido Conselho. Sobre a condução das reuniões, a mesma relatou que:

As reuniões são totalmente democráticas. Inclusive a partir da construção da pauta. Nós definimos a partir das demandas que chegam, uma pauta e trazemos, mas o conselheiro recebe a pauta com antecedência e ele pode sugerir na pauta ser incluído algum assunto que ele entende que seja relevante e necessária a discussão. As decisões são do Colegiado. Mesmo que eu tenha minha opinião própria e meu direcionamento, mas o que prevalece é o voto da maioria.

Quanto ao funcionamento do conselho, a entrevistada descreveu que: 
O Conselho, por meio das Câmaras, tem feito um trabalho bem interessante. Nós temos um colegiado hoje, de 2019 a 2021, que tem demonstrado uma atuação muito boa, estão sendo bem receptivos. Nós estamos dentro das Câmaras e no CME Pleno já organizamos comissões temáticas para estudar alguns atos normativos do Conselho que estavam bastante defasados. Então, esse mandato atual tem sido bastante positivo no sentido dessa participação. Dentre conselhos municipais do Estado do Tocantins, o CME de Palmas tem sido um dos mais atuantes. Tem um quantitativo considerável de membros e a participação é boa, significativa, de membros, onde cada um é ouvido e a gente coloca à apreciação de todos para deliberação.

\section{Acrescentou ainda que:}

O Ministério Público e os órgãos de fiscalização têm sempre se reportado ao CME para saber os encaminhamentos da função realmente inerente ao Conselho. Autorização, como estão as escolas, alguma denúncia. Estão sempre cobrando a atuação do CME e nós estamos sempre respondendo quando chega ao Conselho.

Outro entrevistado foi um Conselheiro, representando o Conselho Municipal da Criança e do Adolescente, sua participação tem apenas 3 meses na gestão atual do referido Conselho. Questionado se participa de outros Conselhos, o mesmo respondeu que participa de vários outros Conselhos. Segundo ele, o Conselho é bastante atuante.

Em uma segunda etapa, já em outubro de 2019, foram aplicados novos questionários e realizadas entrevistas gravadas com os Conselheiros eleitos para o biênio 2019/2021. Foram recebidos 5 questionários respondidos.

Um aspecto negativo levantado diz respeito ao quesito transparência, relevante para uma boa pratica de Gestão Social, conforme leciona Cançado, Pereira e Tenório (2011) "A transparência surge como condição necessária para as outras características, pois o segredo e a assimetria de informação tornam inviável a tomada de decisão coletiva baseada no entendimento esclarecido".

Gráfico 1. Dimensões da Gestão Social no CME/PALMAS.

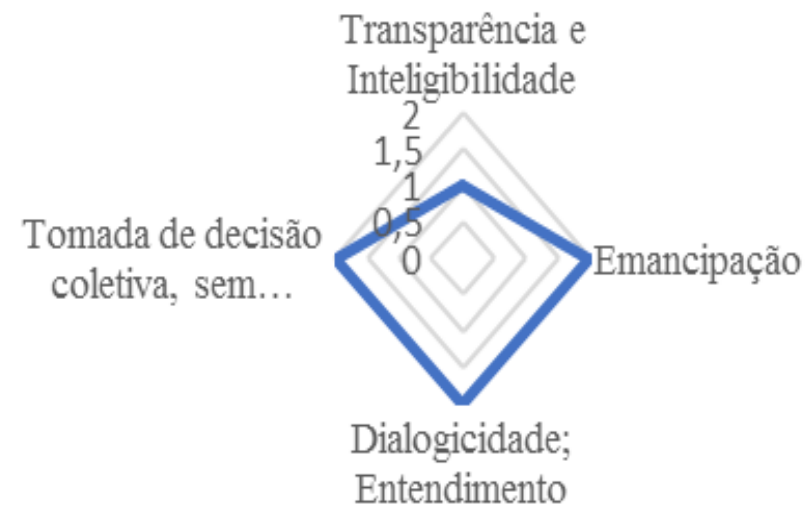

Legenda: 0 - Critério não atendido; 1 - Pouco atendido; 2 Muito atendido; 3 - Totalmente atendido.

Fonte: Elaborado pelos autores com base nas pesquisas realizadas.

Nesse aspecto, impende observar que o CME/PALMAS não dispõe de site atualizado com o calendário e pautas das reuniões. Também não se verificou a publicação das atas na internet.

Gráfico 2. Dimensões da Cidadania Deliberativa no CME/PALMAS.

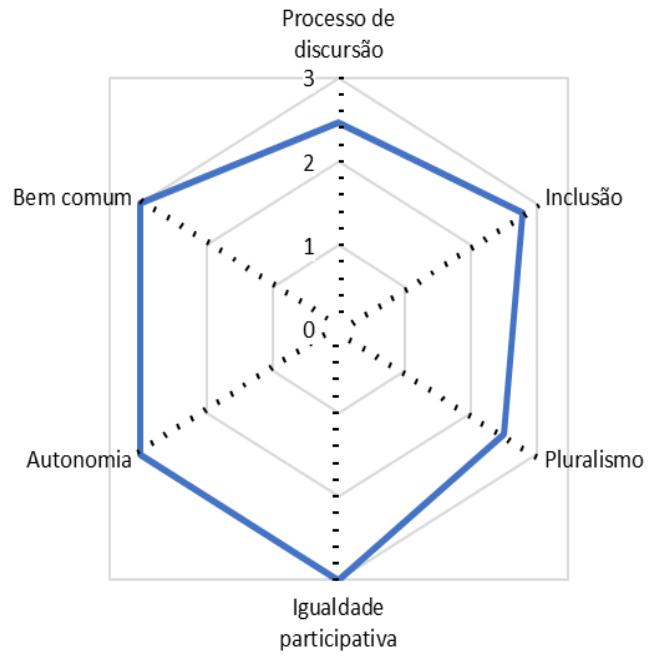

Legenda: 0 - Critério não atendido; 1 - Pouco atendido; 2 Muito atendido; 3 - Totalmente atendido.

Fonte: Elaborado pelos autores com base nas pesquisas realizadas 
Depreende-se das respostas dos questionários levantados que os Conselheiros veem com otimismo e confiança a própria participação no Conselho Municipal de Educação de Palmas.

E1: “(...) eu sempre quis participar do Conselho, mas não tinha chance porque sou tímida, mas desta vez eu encarei e fui atrás do prejuízo (...), acho de extrema importância a gente que trabalha com educação tanto tempo levar nosso conhecimento para a área de gestão".

E2: “(...) uma pena que as pessoas não se interessem em participar mais dos conselhos. É um espaço para todo mundo dar suas próprias sugestões e acompanhar o que acontece naquela área, mas não, ninguém de fora quer saber. É uma pena!"

Gráfico 3. Síntese dos Critérios da Cidadania Deliberativa no CME/PALMAS.

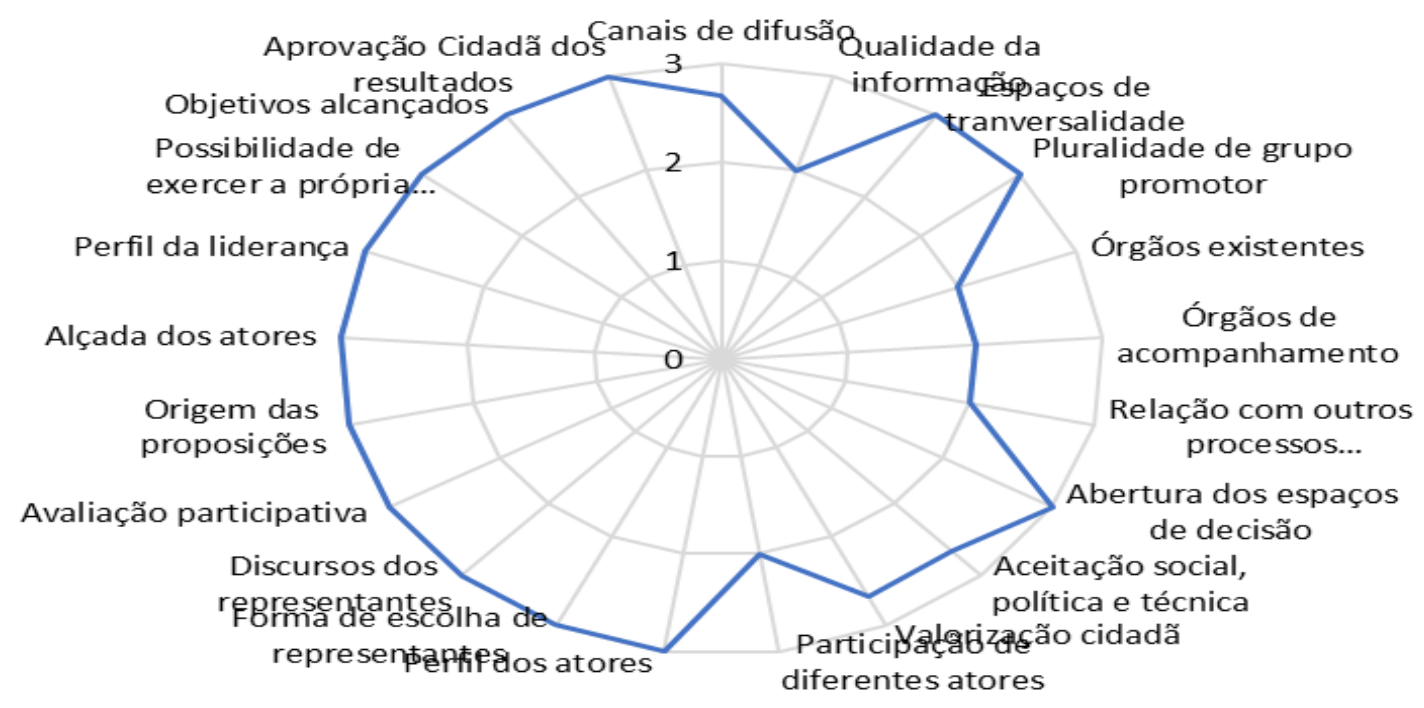

\section{CONSIDERAÇÕES FINAIS}

A investigação a que nos propomos centrouse numa análise, descrição e caracterização do Conselho Municipal de Educação de Palmas - TO, no sentido de fazer o percurso histórico da sua criação e embasamento legal, para que pudesse justificar e fundamentar as suas funções e ações no município no que concerne ao sistema de ensino, suas relações com a sociedade civil e poder público.

O embasamento teórico dos conceitos e princípios que regem os conselhos gestores em geral e conselhos de educação nos direcionaram a olhares mais apreciativos durante o período de convivência naquele Conselho - momento oportuno para observação e análise crítica da rotina da instituição, bem como para coleta de dados documentais e realização das entrevistas.

$\mathrm{O}$ resultado de todo o percurso de pesquisa aponta para as seguintes conclusões prévias: Como a criação do Conselho de Educação do Município se deu quase que concomitante com a criação do município, esse não teve nenhuma ação durante a sua primeira década de existência, o que comprometeu um avanço das suas ações, se se considerarmos o fator tempo.

Por outro lado, pode-se analisar que, nas cinco gestões passadas e na gestão atual há um esforço colaborativo dos conselheiros em pôr em prática as funções peculiares ao Conselho, notadamente nas ações ligadas ao sistema de ensino, como regimentar, fiscalizar, emitir pareceres e certificações. 
No que concerne à composição e escolha de presidentes e conselheiros, embora se perceba uma certa interferência da força político-partidária, o conselho atende aos trâmites legais de eleição. A presidência e todos os conselheiros exercem as suas devidas funções e exercem a função normativa e deliberativa segundo os princípios da coparticipação, em que as tomadas de decisões são tomadas a partir de discussões e votação. Há um respeito às decisões das Câmaras de Ensino e do FUNDEB, o que fortalece mais ainda o caráter democrático.

Quanto à intervenção e fiscalização das políticas públicas, observa-se maior atenção ao poder público em detrimento da participação da comunidade, uma vez que tem conhecimento sobre o Conselho e das suas funções, comprometendo, dessa forma um diálogo entre as demandas da comunidade e as decisões do Conselho.

Nesse sentido, é notória a omissão do Conselho no exercício da função motivadora, já que se fecham nas relações entre Conselho e Poder Público.

As experiências e conhecimentos dos quais nos apropriamos corroboraram a nossa formação enquanto estudiosos da gestão de políticas públicas, bem como gestores no âmbito público, tornando-nos mais críticos e reflexivos para que reconstruamos novos conceitos e paradigmas flexíveis no processo do exercício da cidadania, que deve estar presente em todos os segmentos da sociedade.

\section{REFERÊNCIAS BIBLIOGRÁFICAS}

BRASIL. Constituição Federal do Brasil, 1988.

CANÇADO, A.C; TENÓRIO, F.G. e PEREIRA, J.R. Gestão social: reflexões teóricas e conceituais Cad. EBAPE.BR, v. 9, $\mathrm{n}^{\circ}$ 3, artigo 1, Rio de Janeiro, Set. 2011 p.681-703.
CANÇADO, Anne Caroline M. G. A Gestão Social no Conselho Municipal de Educação de Palmas-TO (Mestrado em Desenvolvimento Regional) Universidade Federal do Tocantins, Palmas, 2018.

CUNILL GRAU, N. Repensando o público através da sociedade: novas formas de gestão pública e representação social. Brasília, DF: ENAP, 1998.

FONSECA, Fábio do Nascimento. Conselhos Municipais de Educação: natureza, papéis e funções.https://www.portaleducacao.com.br/conteud o/artigos/educacao/conselhos-municipais-deeducacao-natureza-papeis-e-funcoes/26730

GARELLI, F. Controle social. In: BOBBIO, N.; MATTEUCCI, N.; PASQUINO, G. (Org.). Dicionário de política. 12. ed. Brasília, DF: Ed. UnB, 1999. 283 $285 \mathrm{p}$.

GOHN, M. G. Conselhos gestores e participação sociopolítica. São Paulo: Cortez, 2001.

Os Conselhos de Educação e a Reforma do Estado. Em Conselhos Gestores de Políticas Públicas. Maria do Carmo A. A. Carvalho e Ana Cláudia C. Teixeira (orgs.). São Paulo, Pólis, 2000.

GOMES, E. G. M. Conselhos gestores de políticas públicas: democracia, controle social e instituições. Dissertação (Mestrado em Administração Pública e Governo) - Escola de Administração de Empresas de São Paulo, Fundação Getúlio Vargas, São Paulo, 2003.

Conselhos gestores de políticas

públicas: aspectos teóricos sobre o potencial de controle social democrático e eficiente. Cad. EBAPE.BR, v. 13, n ${ }^{\circ}$ 4, Artigo 12, Rio de Janeiro, Out./Dez. 2015.

PEROVANO, D.GA. Manual da Metodologia da Pesquisa. Juruá Editora. 1ª ed., 2014.

PREFEITURA MUNICIPAL DE PALMASConselho Municipal de Educação. .https://www.palmas.to.gov.br/servicos/conselhomunicipal-de-educacao-cme/42/

RANIERI, Nina Beatriz. Educação Superior, Direito e Estado na Lei de Diretrizes e Bases: Lei n. 9.394/96. São Paulo: EDUSP/FAPESP, 2000. 